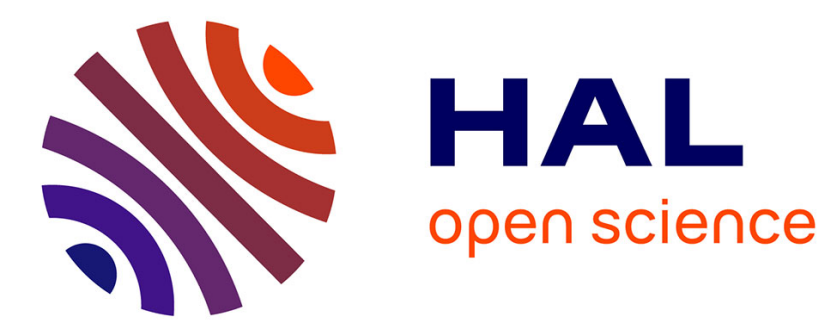

\title{
General Equilibrium With Uncertainty Loving Preferences
}

Aloisio Araujo, Alain Chateauneuf, Juan Pablo Gama, Rodrigo Novinski

\section{To cite this version:}

Aloisio Araujo, Alain Chateauneuf, Juan Pablo Gama, Rodrigo Novinski. General Equilibrium With Uncertainty Loving Preferences. Econometrica, 2018, 86 (5), pp.1859-1871. 10.3982/ECTA14777. hal-03252360

\section{HAL Id: hal-03252360 https://hal.science/hal-03252360}

Submitted on 7 Jun 2021

HAL is a multi-disciplinary open access archive for the deposit and dissemination of scientific research documents, whether they are published or not. The documents may come from teaching and research institutions in France or abroad, or from public or private research centers.
L'archive ouverte pluridisciplinaire HAL, est destinée au dépôt et à la diffusion de documents scientifiques de niveau recherche, publiés ou non, émanant des établissements d'enseignement et de recherche français ou étrangers, des laboratoires publics ou privés. 


\title{
GENERAL EQUILIBRIUM WITH UNCERTAINTY LOVING PREFERENCES
}

\author{
Aloisio Araujo \\ IMPA and FGV EPGE Brazilian School of Economics and Finance \\ Alain Chateauneuf \\ IPAG Business School and Paris School of Economics, Université de Paris I \\ JUAN PABLO GAMA
IMPA \\ RODRIGO NOVINSKI \\ Faculdades Ibmec-RJ
}

\begin{abstract}
More and more economists are finding both empirical and experimental evidence of economic behavior that is well beyond classical economics. In particular, empirical evidence (Jullien and Salanié (2000)) and experimental evidence (Kahneman and Tversky (1979)) supported the importance of risk loving, ambiguity loving, and related behavior in economics. However, these types of preferences have not been analyzed in the general equilibrium literature with a finite number of agents because non-convexity of preferences creates difficulty in proving existence of equilibrium. The main result in this paper provides a set of conditions under which equilibrium exists in such economies.

We show that uncertainty of aggregate wealth, as well as some dominance of the endowment of the risk averters in the economy, play a role in the existence of ArrowDebreu equilibria. This result can be extended to ambiguity in the sense of CEU, Smooth Ambiguity, and Variational Preference.
\end{abstract}

KEYWORDS: General equilibrium, complete financial markets, risk loving, ambiguity, aggregate risk.

\section{INTRODUCTION}

IN RECENT YEARS, more and more economists have found both empirical and experimental evidence of several psychological behaviors that are well beyond the analysis of classical economics. One of the most relevant is the Big-five personality traits model, which has become an important tool to understand the relationship between the complex process of decision making and the large variety of personality traits (see Borghans, Duckworth, Heckman, and ter Weel (2016)). Two of these are ambiguity and risk taking (see Shane, Locke, and Collins (2003)).

In the case of ambiguity, many entrepreneurs and MBA students are more likely to have an appreciation for ambiguity; when probabilities are unknown, their intuition leads them

\footnotetext{
Aloisio Araujo: aloisio@impa.br

Alain Chateauneuf: Alain.Chateauneuf@univ-paris1.fr

Juan Pablo Gama: jpgamat@impa.br

Rodrigo Novinski: rodrigo.novinski@ibmecrj.br

We thank participants at the 10th Annual Cowles GE 2014 Conference, the 13th SAET 2013 Conference, EEA-ESEM 2014, IWGTS 2014, EWGET 2014, LACEA-LAMES 2014, the 15th SAET 2015 Conference, and the 11th World Congress of the Econometric Society for comments. We also thank T. Kehoe, P.A. Chiappori, P. Wakker, T. Strzalecki, C. Azariadis, and Braulio Calagua and all the anonymous referees for their comments and suggestions that improved our work. The authors gratefully acknowledge financial support from CAPES, CNPq, and FAPERJ; Chateauneuf and Gama thank IMPA for the generous financial support from the "Ciências sem Fronteiras" fellowship and from the "Brazilian-French Network in Mathematics".
} 
to see opportunities others miss (see Potamites and Zhang (2006)). More specifically, experimental evidence supports the idea that low-probability gains and high-probability losses are related to ambiguity loving and that high-probability gains and low-probability losses lead to ambiguity aversion (see Wakker (2010) and Trautmann and Van de Kuilen (2015)).

In the case of risk taking, Friedman and Savage (1948) assumed that agents could be risk lovers for medium levels of wealth. Tversky and Kahneman (1992) found a more refined form to represent these changes in attitudes toward risk making the decision makers dependent on a reference point, an idea that has been supported by several experimental studies (see Kahneman and Tversky (1979) and Wakker (2010)) and empirical studies (see Chiappori, Salanié, Salanié, and Gandhi (2012)). In these studies, the four-fold pattern (risk loving for low-probability gains and high-probability losses and risk aversion for high-probability gains and low-probability losses) has also been observed (see Bruhin, Hehr-Duda, and Epper (2016)).

The relationship between these different attitudes and their implication for the existence of an equilibrium remains an important and open question. Unfortunately, a general equilibrium analysis that allows for risk and ambiguity loving attitudes cannot be performed by traditional models with a finite number of agents because an equilibrium may not exist. ${ }^{1}$ This problem is avoided in economies with a continuum of agents (see Aumann (1966)). However, in economies with a continuum of agents, equal agents might make different decisions in a random way, ending up with a mixed strategy equilibrium. Another way to overcome these difficulties is to work in a set of a finite number of lotteries (see Snowberg and Wolfers (2010) as an example) since this structure is considerably simpler. Nevertheless, this is not always economically realistic from a decision-making point of view.

In the present paper, we find sufficient conditions for the existence of equilibria in economies with a finite number of agents with different attitudes toward uncertainty. These conditions require aggregate uncertainty in the economy and the prevalence of the endowments of risk averters in comparison to risk lovers. Under these conditions, risk lovers will buy part of the aggregate risk owned by the risk averters at equilibrium, leading to a mutually beneficial exchange of risk between the agents. Note that our results are obtained in the realistic and more mathematically difficult case in which outcomes are payments in the numeraire.

The aggregate uncertainty conditions sufficient for the existence of equilibrium could be associated with large-scale changes that could occur in the economy; some of these examples are nuclear accidents, extremely powerful earthquakes, tsunamis, severe droughts, floods, hurricanes, and variations of solar radiation. Each of these events has a global impact affecting a large proportion of the population depending on their magnitude.

Our general case includes Smooth Ambiguity (SA) (see Klibanoff, Marinacci, and Mukerji (2005)), Choquet Expected Utility (see Schmeidler (1989), Yaari (1987), and Quiggin (1982), Quiggin (1993)), Maximin Expected Utility (see Gilboa and Schmeidler (1989)), and Variational Preference (see Maccheroni, Marinacci, and Rustichini (2006)). Therefore, our model can also be applied in situations with aggregate uncertainty with unknown probabilities such as war, financial crises, and global warming. In these situations, the ambiguity lovers will be the ones to absorb most of the uncertainty that exists in the economy.

This article is organized as follows: In Section 1, we analyze an Edgeworth box. In Section 2, we study the general case with non completely substitutable goods for agents

\footnotetext{
${ }^{1}$ The difficulties arise from the non-convexity of the preferences.
} 
with non-convex preferences such as ambiguity/risk lovers. In Section 3, we offer some concluding remarks.

\section{RISK LOVING IN THE EDGEWORTH BOX}

\subsection{Example}

In the following example, we see how the existence of equilibrium with risk lovers is strongly related to aggregate risk and the prevalence of the risk averter.

EXAMPLE 1.1: Suppose that each good can be interpreted as a state of the world in an economy with complete markets. Each agent has a utility function $U^{i}\left(x_{1}, x_{2}\right)=$ $1 / 2 u^{i}\left(x_{1}\right)+1 / 2 u^{i}\left(x_{2}\right)$, where $u^{1}(x)=1-e^{-x}$ and $u^{2}(x)=e^{x}-1$. Suppose also that $\omega^{1}=\left(\omega_{1}^{1}, \omega_{2}^{1}\right)$ is the endowment for agent 1 and $\omega^{2}=\left(\omega_{1}^{2}, \omega_{2}^{2}\right)$ is the endowment for agent 2 , and $p=\left(p_{1}, 1-p_{1}\right)$ is the Arrow-Debreu price.

Because agent 2 is a risk lover, the optimal consumption will satisfy $x_{1}^{2}=0$ or $x_{2}^{2}=0$ (see Lemma 2.1 on page 1865). If $x_{1}^{2}=0$, the price must satisfy $p_{1} \geq 1 / 2$, and then, the first-order conditions (FOC) of agent 1 and market clearing imply

$$
\omega_{2}^{1}=\ln \left(\frac{p_{1}}{1-p_{1}}\right)+\omega_{1}+\frac{p_{1}}{1-p_{1}} \omega_{1}^{2},
$$

$x_{1}^{1}=\omega_{1}, x_{2}^{1}=\frac{1}{2} \omega_{2}^{1}+\frac{\omega_{2}^{1} \omega_{1}^{1}}{2\left(\omega_{1}+\omega_{1}^{2}\right)}, x_{1}^{2}=0$, and $x_{2}^{2}=\omega_{2}^{2}+\frac{\omega_{1}^{2} \omega_{2}^{1}}{\omega_{1}+\omega_{1}^{2}}$, where $\omega_{s}=\omega_{s}^{1}+\omega_{s}^{2}$ for $s=1,2$. Since $p_{1} \geq 1 / 2$, for an equilibrium to exist with $x_{1}^{2}=0$, we have

$$
\omega_{2}^{1} \geq \omega_{1}+\omega_{1}^{2} \text {. }
$$

On the other hand, if Equation (1.2) holds, there is a price $\left(p_{1}, 1-p_{1}\right)$ with $p_{1} \geq 1 / 2$ such that Equation (1.1) is satisfied as well as market clearing with the optimal consumption plans defined above, implying the existence of equilibrium with $x_{1}^{2}=0$.

If $x_{2}^{2}=0$, the price must satisfy $p_{1} \leq 1 / 2$, and then,

$$
\omega_{1}^{1}=\ln \left(\frac{1-p_{1}}{p_{1}}\right) \omega_{2}+\frac{1-p_{1}}{p_{1}} \omega_{2}^{2},
$$

$x_{1}^{1}=\frac{1}{2}\left(\omega_{1}^{1}-\omega_{2}^{1}\right)+\frac{\omega_{2}^{1}\left(\omega_{1}^{1}+\omega_{2}+\omega_{2}^{2}\right)}{2\left(\omega_{2}+\omega_{2}^{2}\right)}, x_{2}^{1}=\omega_{2}, x_{1}^{2}=\omega_{1}^{2}-\omega_{2}^{2}+\frac{\omega_{2}^{2}\left(\omega_{1}^{1}+\omega_{2}+\omega_{2}^{2}\right)}{\omega_{2}+\omega_{2}^{2}}$, and $x_{2}^{2}=0$. Since $p_{1} \leq 1 / 2$, we have that the endowments must satisfy

$$
\omega_{1}^{1} \geq \omega_{2}+\omega_{2}^{2}
$$

Similarly as before, if Equation (1.4) holds, there is an equilibrium price $\left(p_{1}, 1-p_{1}\right)$ for which $p_{1} \leq 1 / 2$, Equation (1.3), and $x_{2}^{2}=0$ are satisfied.

Since any possible equilibrium allocation satisfies $x_{1}^{2}=0$ or $x_{1}^{2}=0$, the existence of equilibrium is equivalent to having Condition (1.2) or $(1.4),{ }^{2}$ which is equivalent to

$$
\omega_{2}=\omega_{2}^{1}+\omega_{2}^{2} \geq \omega_{1}+\left(\omega_{1}^{2}+\omega_{2}^{2}\right) \text { or } \omega_{1}=\omega_{1}^{1}+\omega_{1}^{2} \geq \omega_{2}+\left(\omega_{1}^{2}+\omega_{2}^{2}\right) .
$$

\footnotetext{
${ }^{2}$ Note that these conditions are mutually exclusive. Therefore, there is uniqueness of equilibrium in this example.
} 


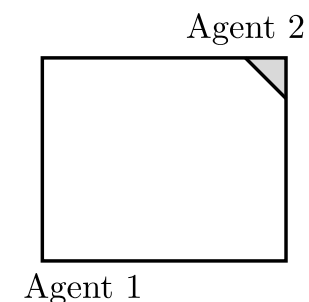

FIGURE 1.-Endowment distributions where equilibrium exists (gray region) in Example 1.1 in presence of low aggregate risk $\left(\omega_{1}=1.2 \omega_{2}\right)$.

Therefore, a large enough aggregate risk is necessary and sufficient to ensure the existence of equilibrium. In other words, the aggregate uncertainty must be at least equal to the sum of the endowments of the risk lover.

We can interpret $\omega_{1}^{2}+\omega_{2}^{2}$ as the lowest amount of risk that the risk lover can consume, implying that any level of aggregate risk lower than this benchmark is inconsistent with the existence of equilibrium due to a violation of market clearing.

As a consequence of Condition (1.5), there are fewer possible endowment distributions that eliminate the gap between optimal consumption and the initial endowment in all states when the presence of aggregate risk is low.

As Figures 1 and 2 show, there is a clear difference between economies with substantial risk and economies with almost no risk. For example, in Figure 1, the Edgeworth box (EB) has an aggregate risk ${ }^{3}$ of $20 \%$, and as a consequence, the possible endowment distributions for which equilibrium exists are restricted to endowment distributions with a very poor agent $2 .{ }^{4}$ However, when aggregate risk is large as in Figure 2, the existence of equilibrium is less affected by large endowment distributions provided to the risk lover, which implies an increment of the endowment allocations for which equilibrium exists.

REMARK 1.1: Note that the risk lover does not have a null importance in the economy as Aumann (1966) suggested. What Condition (1.5) requires is a large amount of aggregate risk to allow the trade between agents, as mentioned above. Figure 3 illustrates how agents exchange the existing risk in the economy.

Agent 2

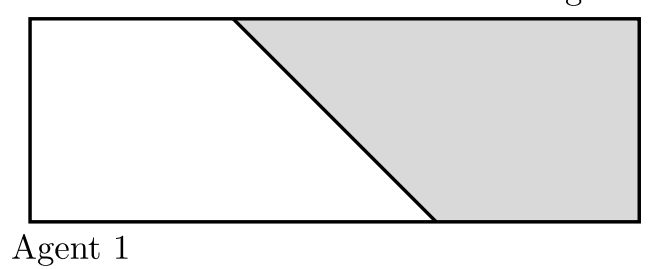

FIGURE 2.-Endowment distributions where equilibrium exists (gray region) in Example 1.1 in presence of large aggregate risk $\left(\omega_{1}=3 \omega_{2}\right)$.

\footnotetext{
${ }^{3}$ Aggregate risk is defined as the ratio between the aggregate endowments $\omega_{1}$ and $\omega_{2}$.

${ }^{4}$ Agent 2 might be more than 10 times poorer than agent 1 .
} 


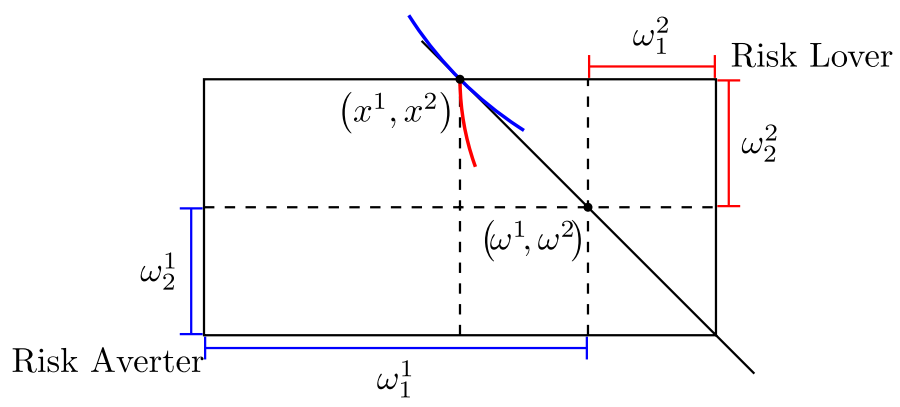

FIGURE 3.-Edgeworth box.

\subsection{Analysis for EU Decision Makers}

In this subsection, let us analyze an Edgeworth box with two EU agents, $U^{i}(x)=$ $\pi u^{i}\left(x_{1}\right)+(1-\pi) u^{i}\left(x_{2}\right), \forall i=1,2$, where $\pi \in(0,1)$ is the probability of the first state, $u^{1} \in C^{1}(0, \infty) \cap C[0, \infty)$ is the utility index of agent 1 , and $u^{2} \in C[0, \infty)$ is the utility index of agent 2. $u^{1}$ is a strictly increasing and concave function that satisfies $\lim _{x \rightarrow \infty} u^{1^{\prime}}(x)=0$, and $u^{2}$ is an increasing and convex function satisfying $u^{2}(0)=0$.

PROPOSITION 1.1: Under our hypotheses, including Inada, there are $\underline{\omega}_{1}^{1} \geq 0$ and $\underline{\omega}_{2}^{1} \geq 0$ such that:

1. There is an AD-equilibrium if and only if $(a) \omega_{1}^{1} \geq \underline{\omega}_{1}^{1}$ and then $x_{2}^{2}=0$, or $(b) \omega_{2}^{1} \geq \underline{\omega}_{2}^{1}$ and then $x_{1}^{2}=0$.

2. There is a unique normalized price $p=\left(p_{1}, 1-p_{1}\right) \in \Delta_{++}^{1}$ for the AD-equilibrium, which is the solution of

$$
\omega_{1}^{1}=u^{1^{(-1)}}\left(\left(\frac{p_{1}}{1-p_{1}}\right)\left(\frac{1-\pi}{\pi}\right) u^{1^{\prime}}\left(\omega_{2}\right)\right)+\frac{1-p_{1}}{p_{1}} \omega_{2}^{2}
$$

for (a), and the solution of

$$
\omega_{2}^{1}=u^{1^{(-1)}}\left(\left(\frac{1-p_{1}}{p_{1}}\right)\left(\frac{\pi}{1-\pi}\right) u^{1^{\prime}}\left(\omega_{1}\right)\right)+\frac{p_{1}}{1-p_{1}} \omega_{1}^{2}
$$

for (b).

The proof of Proposition 1.1 and its extension to cases without Inada's condition are in Appendix A.1.

REMARK 1.2: $\underline{\omega}_{1}^{1}$ and $\underline{\omega}_{2}^{1}$ are the values that one would obtain for $\omega_{1}^{1}$ and $\omega_{2}^{1}$, respectively, in (1.6) and in (1.7) taking $p$ as the solution of $\pi u^{2}\left(p \omega^{2} / p_{1}\right)=(1-$ $\pi) u^{2}\left(p \omega^{2} /\left(1-p_{1}\right)\right)$.

The necessary and sufficient conditions of Proposition 1.1 not only prove the existence of equilibrium but also ensure its uniqueness. Additionally, Proposition 1.1 shows that, to ensure the existence of equilibrium, a minimum level of endowment in one of the states of the risk averter is needed. Therefore, if we have economies in which the aggregate risk is 
relatively large and most of this wealth is in hands of the risk averter, ${ }^{5}$ equilibrium would exist as a consequence of the exchange of risk with the risk lover. However, in some rare cases,${ }^{6}$ an equilibrium can exist in economies with no aggregate risk.

\section{EQUILIBRIUM WITH NON-CONVEX AGENTS: GENERAL CASE}

\subsection{Model}

Let us define a model with $I+J$ agents where each agent $i$ is characterized by a utility function given by $U^{i}: \mathbb{R}_{+}^{S} \rightarrow \mathbb{R}$ and an Arrow-Debreu constraint given by $B\left(p, \omega^{i}\right):=$ $\left\{x: p x \leq p \omega^{i}\right\}$, where $p \in \Delta_{+}^{S-1}$ is the price and $\omega^{i} \in \mathbb{R}_{+}^{S}$ is the initial endowment for the agent $i$. In this economy, there are $S$ states of nature and one consumption good in each of them.

We will say that $\left(p,\left(x^{i}\right)_{i}\right)$ is an equilibrium (an Arrow-Debreu equilibrium) when $x^{i}$ is optimal for $U^{i}$ subject to the AD-constraint, and $\sum_{i} \omega^{i}=\sum_{i} x^{i}$.

From this point onward, we will consider two different types of behavior. The agents $i=1, \ldots, I$ will be of Type $A$ and the agents $j=I+1, \ldots, I+J$ will be of Type $B$.

The agents of Type $A$ satisfy:

A1: Utility function, $U^{i}$, strictly increasing, concave.

A2: For any $s, s^{\prime}$ and $\left\{x^{n}\right\}_{n \in \mathbb{N}} \in \mathbb{R}_{+}^{S}$ such that $\left\{x_{s}^{n}\right\}_{n},\left\{x_{s^{\prime}}^{n}\right\}_{n}$ are bounded away from zero from below, if $x_{s^{\prime}}^{n} / x_{s}^{n} \rightarrow 0$,

$$
\lim _{n \rightarrow \infty}\left(\max _{T \in \partial U\left(x^{n}\right)} \frac{T \circ e_{s}}{T \circ e_{s^{\prime}}}\right)=0,
$$

where $e_{s}$ is the $s$-canonical vector.

A3: For any $s, s^{\prime}$ and $\left\{x^{n}\right\}_{n \in \mathbb{N}} \in \mathbb{R}_{+}^{S}$ such that $\left\{x_{s}^{n}\right\}_{n},\left\{x_{s^{\prime}}^{n}\right\}_{n}$ are bounded from above and $\left\{x_{s^{\prime}}^{n}\right\}_{n}$ is bounded away from zero from below, we have that

$$
\liminf _{n \rightarrow \infty}\left(\min _{T \in \partial U\left(x^{n}\right)} \frac{T \circ e_{s}}{T \circ e_{s^{\prime}}}\right)>0 .
$$

Hypothesis A2 is related to the marginal substitution rate between two states for large consumption levels; more precisely, when demand increases in state $s$ compared to state $s^{\prime}$, the marginal demand between the state $s$ and $s^{\prime}$ converges to zero. In other words, it says that arbitrarily large consumption in some states does not nullify the marginal utility of consuming any other good or state.

Hypothesis A3 says that the marginal utility between state $s$ and $s^{\prime}$ is bounded away from zero for every sequence of consumption with bounded consumption in both states. In other words, it says that the marginal utility in one state is not nullified if the consumption is bounded in that state. Intuitively, Hypotheses A2 and A3 ensure the existence of some independence among the states or goods in the economy such that any state or good is not a perfect substitute of any other in the economy.

\footnotetext{
${ }^{5}$ In the sense of possession of endowments with large variations between states.

${ }^{6}$ It requires extremely large differences among agents and states.
} 
Agents of Type $B$ satisfy:

B1: The utility function is strictly increasing and convex.

The endowments are given by $\left(\omega_{1}^{i}, \ldots, \omega_{S}^{i}\right) \gg 0$. And we denote $\omega_{s}:=\sum_{i=1}^{I+J} \omega_{s}^{i}$, $\forall s=1, \ldots, S$.

Because Type $B$ agents have convex utility functions, they have incentives to specialize their consumption as much as possible.

LEMMA 2.1: Given price $p, a$ B agent $j$ has an optimal solution given by

$$
x_{s}^{j}= \begin{cases}0 & \text { for } s \neq s_{0}, \\ \frac{1}{p_{s_{0}}}\left[p \omega^{j}\right] & \text { for } s=s_{0},\end{cases}
$$

for some $s_{0}=1, \ldots, S$. Moreover, if the utility function $U^{I+i}$ is strictly convex, any optimal solution has the form of $x^{I+i}$ for some $s_{0}$.

The proof can be found in Appendix A.1.

Note that if there is at least one agent of Type $B$ that has a nonlinear utility function, we cannot apply the standard techniques of existence of equilibrium, which include Shafer (1976) and He and Yannelis (2016).

As in Example 1.1, we will show that the existence of aggregate risk helps the match of hedging of Type $A$ agents and specialization of Type $B$ agents. However, the former agents must have proportionally more wealth in one state to allow the specialization of the latter without violating market clearing.

THEOREM 2.1: If the aggregate endowment of Type A agents is sufficiently large in a state $s$ compared to the aggregate endowment in other states, there is an equilibrium for the economy.

The proof can be found in Appendix A.2.

As mentioned above, Hypotheses A2 and A3 imply some independence among states or goods ensuring that changes in the level of aggregate uncertainty will affect the marginal rates of substitution of the $A$ agents.

Our result indicates that when there is a large amount of wealth in one state for the $A$ agents, they are willing to transfer this excess of uncertainty as much as they can to the $B$ agents, allowing the latter to improve their consumption.

A possible interpretation of our aggregate uncertainty hypothesis is related to the possibility of large-scale changes that can occur in the economy; some of these examples are nuclear accidents, wars, financial crises, global warming, and changes in solar radiation. Each of the events described has a global impact affecting almost everyone depending on the magnitude of the phenomenon.

If the $B$ agents cannot specialize very much, the aggregate risk needed in the economy to have an equilibrium is very low. Therefore, any regulation that reduces the specialization of the $B$ agents also reduces the amount of aggregate risk needed to ensure equilibrium.

REMARK 2.1: Note that our result can also be implemented in economies with agents given by Smooth Ambiguity decision makers (see Klibanoff, Marinacci, and Mukerji (2005)), Choquet Expected Utility decision makers (see Schmeidler (1989)), RankDependent Expected Utility decision makers (see Quiggin (1982), Quiggin (1993) and Yaari (1987)), and Variational Preferences (see Maccheroni, Marinacci, and Rustichini (2006)). 
Since our result can be implemented in the case of a large variety of ambiguous decision makers, we can also justify the existence of some level of aggregate uncertainty with events for which the probabilities cannot be known in advance, such as wars, financial crises, and global warming. In the case of wars, the complexity of geopolitics makes it completely impossible to have an accurate probability of such an event. In the case of financial crises, any algorithm or model that tries to establish an accurate probability of such an event will be overloaded by the large amount of variables that must be considered, such as all the properties of each market, the variety of events that could trigger or enhance a crisis, and the unknown information such as demographic trends, immigration, and growth of the economy. In the case of global warming, the lack of data on previous global warming periods and the unknown consequences of the current global changes make it completely impossible to establish any possible future event with an accurate probability.

In the case of Expected Utility decision makers, the previous result can also be extended to include the case in which the risk lovers specialize in different states (see Remark A.2 in Appendix A.1).

\section{CONCLUSIONS}

Given the importance of risk loving and especially ambiguity loving in financial markets, the exchange of aggregate risk between risk/ambiguity lovers and risk/ambiguity averters is an important problem to address since it has not been analyzed in general equilibrium theory.

We provided conditions in terms of sufficient aggregate uncertainty for a large class of decision makers encompassing $S A$ (see Klibanoff, Marinacci, and Mukerji (2005)), $C E U$ (see Schmeidler (1989)), and VPs (see Maccheroni, Marinacci, and Rustichini (2006)); under these conditions, we were able to prove the existence of equilibria. ${ }^{7}$ These conditions suggest that a minimum level of aggregate risk is needed to enable trade between both types of agents, allowing matching between the desire for hedging of risk/ambiguity averters and the desire for speculation of risk/ambiguity lovers.

The aggregate uncertainty conditions mentioned above can be associated with largescale changes that can occur in the economy due to external phenomena such as nuclear accidents, extremely powerful earthquakes, tsunamis, severe droughts, floods, hurricanes, variation in solar radiation, nuclear accidents, wars, financial crises, and global warming. Each of these events has a global impact affecting a considerably large proportion of the population depending on their magnitude.

The analysis mentioned above can be useful in theoretically and numerically analyzing the influence of risk/ambiguity loving in economies with financial markets and addressing how volatility and welfare can be affected by these agents in a similar form, as Rigotti, Shannon, and Strzalecki (2008) did in the case of ambiguity aversion.

\section{APPENDIX: PROOFS}

\section{A.1. Proofs of Section 2}

Proof OF Lemma 2.1: Since all $B$ agents have a convex utility function, for any $\alpha \in[0,1], U^{i}\left(\alpha x_{1}+(1-\alpha) x_{2}\right) \leq \alpha U^{i}\left(x_{1}\right)+(1-\alpha) U^{i}\left(x_{2}\right) \leq \max _{t}\left\{U^{i}\left(x_{t}\right)\right\}$, which

\footnotetext{
${ }^{7}$ For the existence of Pareto optima (see Araujo, Bonnisseau, Chateauneuf, and Novinski (2016)).
} 
implies that there is an optimal consumption on the boundary of the budget set, $\left\{\left(0, \ldots, \frac{1}{p_{s}}\left[p \omega^{i}\right], \ldots, 0\right)\right\}_{s=1}^{S}$.

ProOf OF Proposition 1.1: Let us prove that there is an equilibrium for the economy. For any $p_{1} \in(0,1)$, since agent 2 has a strictly convex and strictly increasing utility index, the optimal solution must be on the frontier of the budget set; therefore, the possible optimal solutions are $\left(\frac{p \omega^{2}}{p_{1}}, 0\right)$ and $\left(0, \frac{p \omega^{2}}{1-p_{1}}\right)$ (see Lemma 2.1).

From now on, we will analyze the case in which agent 2 specializes in the first state. Consider $\bar{p}_{1} \in(0,1)$ and $\bar{p}=\left(\bar{p}_{1}, 1-\bar{p}_{1}\right)^{8}$ as the solution of

$$
\pi u^{2}\left(\frac{\bar{p} \omega^{2}}{\bar{p}_{1}}\right)=(1-\pi) u^{2}\left(\frac{\bar{p} \omega^{2}}{1-\bar{p}_{1}}\right)
$$

$\underline{\omega}_{1}^{1}>0$ as the solution of Equation (1.6) with $p_{1}=\bar{p}_{1}$ and $\omega:(0,1) \rightarrow(0, \infty)$ as $\omega(p)=$ $u^{1^{\prime(-1)}}\left(\left(\frac{p}{1-p}\right)\left(\frac{1-\pi}{\pi}\right) u^{1^{\prime}}\left(\omega_{2}\right)\right)+\frac{1-p}{p} \omega_{2}^{2},{ }^{9}$ which is strictly decreasing on $p$.

Now let us prove that for each $\omega_{1}^{1} \geq \underline{\omega}_{1}^{1}$, there is an equilibrium when the price ( $p_{1}, 1-$ $p_{1}$ ) satisfies $p_{1}=\omega^{-1}\left(\omega_{1}^{1}\right)$.

If $\omega_{1}^{1} \geq \underline{\omega}_{1}^{1}$, then $p_{1} \leq \bar{p}_{1}$ so $\pi u^{2}\left(\frac{p \omega^{2}}{p_{1}}\right) \geq(1-\pi) u^{2}\left(\frac{p \omega^{2}}{1-p_{1}}\right)$.

This implies that the optimal consumption of agent 2 is $\left(\frac{p \omega^{2}}{p_{1}}, 0\right)$.

Now, the FOC for agent 1 implies that $\pi u^{1^{\prime}}\left(x_{1}^{1}\right)=p_{1} \mu,(1-\pi) u^{1^{\prime}}\left(x_{2}^{1}\right)=\left(1-p_{1}\right) \mu$ and

$$
p_{1} x_{1}^{1}+\left(1-p_{1}\right) x_{2}^{1}=p_{1} \omega_{1}^{1}+\left(1-p_{1}\right) \omega_{2}^{1},
$$

for $\mu>0$. Therefore, $\mu=\frac{1-\pi}{1-p} u^{1^{\prime}}\left(\omega_{2}\right)$ and

$$
\left(x_{1}^{1}, x_{2}^{1}\right)=\left(u^{1^{(-1)}}\left(\left(\frac{p}{1-p}\right)\left(\frac{1-\pi}{\pi}\right) u^{1^{\prime}}\left(\omega_{2}\right)\right), \omega_{2}\right)
$$

is the optimal solution for agent 1.

Since we have $x_{2}^{1}+x_{2}^{2}=\omega_{2}$ and $x_{1}^{1}+x_{1}^{2}=u^{1^{\prime(-1)}}\left(\left(\frac{p}{1-p}\right)\left(\frac{1-\pi}{\pi}\right) u^{1^{\prime}}\left(\omega_{2}\right)\right)+\omega_{1}^{2}+\frac{1-p}{p} \omega_{2}^{2}=$ $\omega_{1}^{1}+\omega_{1}^{2}$, this concludes the proof of existence of equilibrium when $x_{1}^{2} \neq 0$, that is, the risk lover specializes in state 1 . The proof is analogous when $x_{2}^{2} \neq 0$.

Now, let us prove the converse. Suppose that there is an equilibrium $(\hat{p}, \hat{x})$ with $\hat{x}_{1}^{2} \neq 0$ for the economy defined by endowments $\left(\omega^{1}, \omega^{2}\right)$; then $\hat{x}_{2}^{1}=\omega_{2}$. Since the risk lover is specializing in state $1, \hat{p}$ satisfies

$$
\pi u^{2}\left(\frac{\hat{p} \omega^{2}}{\hat{p}_{1}}\right)-(1-\pi) u^{2}\left(\frac{\hat{p} \omega^{2}}{1-\hat{p}_{1}}\right) \geq 0
$$

Now, let us define a function $f:(0,1) \rightarrow \mathbb{R}$ as $f(p):=\pi u^{2}\left(\frac{(p, 1-p) \omega^{2}}{p}\right)-$ $(1-\pi) u^{2}\left(\frac{(p, 1-p) \omega^{2}}{1-p}\right)$. Note that $f$ is strictly decreasing and that $\bar{p}_{1}$ is the greatest $p \in(0,1)$

\footnotetext{
${ }^{8}$ The uniqueness of $\bar{p}_{1}$ is a consequence of $u^{2}$ being strictly increasing, $u^{2}(0)=0, u^{2}(x) \rightarrow \infty$ when $x \rightarrow \infty$, and that the left part of Equation (A.1) is decreasing and the right part is increasing on $\bar{p}_{1}$.

${ }^{9} \underline{\omega}_{1}^{1}$ and $\omega(\cdot)$ are well defined since, $u^{1}$ being strictly concave, $u^{1^{\prime}}(0)=\infty$ and $u^{1^{\prime}}(\infty)=0$.
} 
such that $f(\bar{p})=0$; therefore, $\hat{p}_{1} \leq \bar{p}_{1}$. And due to the FOC of agent 1 and market clearing, $x_{2}^{1}=\omega_{2}, x_{1}^{1}=u^{1^{\prime(-1)}}\left(\left(\frac{\hat{p}}{1-\hat{p}}\right)\left(\frac{1-\pi}{\pi}\right) u^{1^{\prime}}\left(\omega_{2}\right)\right)$, and $x_{1}^{1}+x_{1}^{2}=u^{1^{\prime(-1)}}\left(\left(\frac{\hat{p}}{1-\hat{p}}\right)\left(\frac{1-\pi}{\pi}\right) u^{1^{\prime}}\left(\omega_{2}\right)\right)+$ $\omega_{1}^{2}+\frac{1-\hat{p}}{\hat{p}} \omega_{2}^{2}=\omega_{1}^{1}+\omega_{1}^{2}$, which is equivalent to

$$
\omega_{1}^{1}=u^{1^{\prime(-1)}}\left(\left(\frac{\hat{p}}{1-\hat{p}}\right)\left(\frac{1-\pi}{\pi}\right) u^{1^{\prime}}\left(\omega_{2}\right)\right)+\frac{1-\hat{p}}{\hat{p}} \omega_{2}^{2},
$$

which clearly implies that $\omega_{1}^{1} \geq \underline{\omega}_{1}^{1}$, which concludes the proof.

Q.E.D.

REMARK A.1: In absence of Inada's condition, Condition (1.6) can be replaced by

$$
\omega_{1}^{1}=u^{1^{\prime(-1)}}\left(\left(\left(\frac{p_{1}}{1-p_{1}}\right)\left(\frac{1-\pi}{\pi}\right) u^{1^{\prime}}\left(\omega_{2}\right)\right) \wedge u^{1^{\prime}}(0)\right)+\frac{1-p_{1}}{p_{1}} \omega_{2}^{2},
$$

and Condition (1.7) can be replaced by

$$
\omega_{2}^{1}=u^{1^{\prime}(-1)}\left(\left(\left(\frac{1-p_{1}}{p_{1}}\right)\left(\frac{\pi}{1-\pi}\right) u^{1^{\prime}}\left(\omega_{1}\right)\right) \wedge u^{1^{\prime}}(0)\right)+\frac{p_{1}}{1-p_{1}} \omega_{1}^{2} .
$$

PROOF: Due to the FOC, to guarantee that agent 1 has a positive consumption in each state, it is enough to show that

$$
\left(\frac{1-p_{1}}{p_{1}}\right)\left(\frac{\pi}{1-\pi}\right) u^{1^{\prime}}\left(\frac{p_{1} \omega_{1}^{1}+\left(1-p_{1}\right) \omega_{2}^{1}}{p_{1}}\right)<u^{1^{\prime}}(0)
$$

for any $p_{1} \leq \bar{p}_{1}$ where $\omega_{1}^{1}$ satisfies Equation (A.2). And since $u^{1^{\prime}}$ is strictly decreasing and $\omega_{2}^{1}>0$, we have that

$$
\left(\frac{1-p_{1}}{p_{1}}\right)\left(\frac{\pi}{1-\pi}\right) u^{1^{\prime}}\left(\frac{p_{1} \omega_{1}^{1}+\left(1-p_{1}\right) \omega_{2}^{1}}{p_{1}}\right)<\frac{\left(1-p_{1}\right) \pi}{p_{1}(1-\pi)} u^{1^{\prime}}\left(\omega_{1}^{1}\right),
$$

and then, using Equation (A.2) and the properties of $u^{1}$, we have

$$
\frac{\left(1-p_{1}\right) \pi}{p_{1}(1-\pi)} u^{1^{\prime}}\left(\omega_{1}^{1}\right)<\frac{\left(1-p_{1}\right) \pi}{p_{1}(1-\pi)}\left(\left(\frac{p_{1}(1-\pi)}{\left(1-p_{1}\right) \pi} u^{1^{\prime}}\left(\omega_{2}\right)\right) \wedge u^{1^{\prime}}(0)\right)<u^{1^{\prime}}(0) .
$$

Finally, we can apply the proof of Proposition 1.1 to finish the proof. Note that the case of Equation (A.3) is analogous.

Q.E.D.

REMARK A.2: Given $\left\{\omega_{s}^{i}\right\}_{s, i}$, if there are $R$ states, $1 \leq s_{1}, \ldots, s_{R} \leq S$ and $0<k<K$, with $K$ sufficiently large such that:

1. (Symmetry) the probability, $\pi_{s_{r}}$, is the same for all $r$ and $J=R \tilde{J}$ with $\tilde{J} \in \mathbb{N}$ and $\omega^{I+j_{1}}=\omega^{I+j_{2}}$ for $j_{1}=\tilde{j} R+l_{1}$ and $j_{2}=\tilde{j} R+l_{2}$ where $1 \leq l_{1}, l_{2} \leq R$ and $0 \leq \tilde{j}<R$,

2. (Boundedness) $\sum_{i \leq I} \omega_{s_{r}}^{i}=\sum_{i \leq I} \omega_{s_{r^{\prime}}}^{i} \geq K$ and $\sum_{i>I} \omega_{s_{r}}^{i} \leq k$ for all $r, r^{\prime}=1, \ldots, R$, and $\sum_{i} \omega_{s^{\prime}}^{i} \leq k$ for $s^{\prime} \neq s_{r}$ for all $r=1, \ldots, R$, then, there is an equilibrium for the economy with $p \in \Delta_{++}^{S-1}$.

ProOF: We define a fictitious economy in which each $\tilde{j} R+1, \ldots,(\tilde{j}+1) R$ will specialize in $s_{1}, \ldots, s_{R}$, respectively. And, using 1 ., we ensure that in this fictitious economy, the prices must satisfy $p_{s_{1}}=\cdots=p_{s_{R}}$, which concludes the proof. Q.E.D. 


\section{A.2. Proof of Theorem 2.1}

PROOF: Without loss of generality, we will analyze the case in which $\sum_{i \leq I} \omega_{1}^{i}$, the aggregate endowment of the Type $A$ agents is large in the first state compared to aggregate endowment in other states and the aggregate endowment of the Type $B$ agents in the first state. Therefore, Theorem 2.1 can be rewritten as follows: for every endowment allocation that satisfies $\sum_{i \leq I} \omega_{1}^{i} \gg \max \left\{\sum_{j \leq J} \omega_{1}^{I+j}, \max _{s=2, \ldots, S} \bar{\omega}_{s}\right\},{ }^{10}$ the economy has an equilibrium. Therefore, if we define

$$
K=\sum_{i \leq I} \omega_{1}^{i} \quad \text { and } \quad K^{\prime}=\max \left\{\sum_{j \leq J} \omega_{1}^{I+j}, \max _{s=2, \ldots, S} \bar{\omega}_{s}\right\},
$$

to prove Theorem 2.1, it is enough to ensure that there will be an equilibrium for any economy that satisfies that $K$ is large enough compared to $K^{\prime}$.

The idea is to define a fictitious convex economy that satisfies the standard conditions for existence of equilibrium and then, for $K$ large enough and $K^{\prime} \ll K$, the equilibrium of the fictitious economy is in fact an equilibrium for the initial non-convex economy. To do so, we will use some special properties that the equilibrium price has when $K$ is large enough.

Let us define the fictitious economy with the same number of agents, $I+J$, and the same endowments $\left\{\left(\omega_{1}^{i}, \ldots, \omega_{S}^{i}\right)\right\}_{i=1}^{I+J}$ with utility functions $\left\{V^{i}\right\}_{i}$.

Each agent $i=1, \ldots, I$ is defined by the same utility function, that is, $V^{i}=U^{i}$, and the same budget constraint as in the initial economy. However, for an agent $i=I+1, \ldots, I+$ $J$, the utility function is $V^{i}(x):=x_{1}$ and the same budget constraint. As a consequence, there is an equilibrium $\left(\left(x^{i}\right)_{i=1}^{I+J}, p\right)$ for the fictitious economy.

Now, in order to prove that the equilibrium for the fictitious economy is, in fact, an equilibrium for the initial economy, it is necessary to prove that the allocation $x^{i}$ is optimal for the consumers in the initial economy. Note that, for an agent $i=1, \ldots, I$ in the original economy, the allocation $x^{i}$ is also optimal.

Our goal is to ensure that there is $\underline{K} \geq 0$ such that if $K \geq \underline{K}$, the agent $i=I+1, \ldots, I+J$ maximizes his consumption at $x^{i}$ for every $i$. The idea of this part is to ensure that for $K$ large enough, all agents will have enough incentives to buy more in state 1 than in the other states in such a way that all the agents of Type $B$ will consume in the first state or good. These incentives are perceived by the agents as a lower price in state 1 compared to the other states.

LEMMA A.1: Under the same assumptions, for every sequence of fictitious economies with endowment allocation $\left\{\omega^{i, n}\right\}_{n \in \mathbb{N}}$ such that $\left\{K^{n}, K^{\prime n}\right\}_{n \in \mathbb{N}}$ defined by Equation (A.4) satisfies $\lim _{n \rightarrow \infty} K^{n}=\infty$ and $K^{\prime n}$ is bounded, $p_{1}^{n} \rightarrow 0$ when $n \rightarrow \infty$ and $\left\{p_{s}^{n}\right\}_{n}$ is bounded away from zero for every $s \neq 1$.

PROOF: Since $p^{n} \in \Delta_{+}^{S-1}$, without loss of generality, we can assume that $p^{n} \rightarrow \hat{p} \in \Delta_{+}^{S-1}$. Now, let us separate the proof into two parts:

1. Let us show that $\hat{p}_{1}=0$. So, assume that $\hat{p}_{1}>0$.

Since $K^{n} \rightarrow \infty$, there exist at least one agent $(\bar{i} \leq I)$ and a subsequence $\left\{n_{k}\right\}_{k \in \mathbb{N}}$ such that $p^{n_{k}} \omega^{n_{k}, \bar{i}}$ is unbounded, and the agent's consumption in the first state is also unbounded (which implies that, for $k$ large enough, $x_{1}^{n_{k}, \bar{i}}>0$ ) implying that the FOC in

\footnotetext{
${ }^{10} \bar{\omega}_{s}$ is the aggregate endowment in state $s$.
} 
state 1 is satisfied with equality. Therefore, for $k$ large enough and $\varepsilon \in\left(0, \hat{p}_{1}\right)$, there is

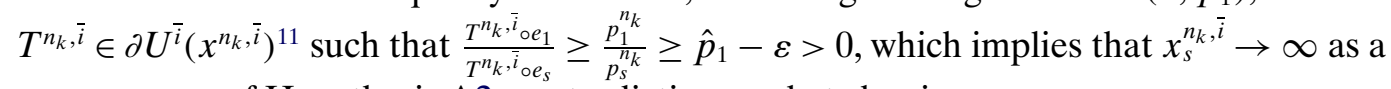
consequence of Hypothesis A2, contradicting market clearing.

2. Let us show now that $\hat{p}_{s}>0$ for every $s \neq 1$. So, let us assume that there exists a state $s^{\prime} \neq 1$ such that $\hat{p}_{s^{\prime}}=0$.

Let $s$ be a state such that $\hat{p}_{s}>0$. Due to market clearing, there exists an agent $i_{n} \leq I$ such that $x_{s}^{n, i_{n}} \geq \bar{\omega}_{s}^{n} /(I+J)>0$ implying that the FOC is satisfied with equality for the agent $i_{n}$ in state $s$. As a consequence, there is $T^{n, i_{n}} \in \partial U^{i_{n}}\left(x^{n, i_{n}}\right)$ such that $\frac{T^{n, i_{n}} \circ e_{s^{\prime}}}{T^{n, i_{n} \circ e_{s}}} \leq \frac{p_{s^{\prime}}^{n}}{p_{s}^{n}}$. Since $x_{s}^{n, i_{n}}$ is bounded away from zero from below and from above by $\max _{n} K^{\prime n}$, and $x_{s^{\prime}}^{n, i_{n}}$ is bounded from above by $\max _{n} K^{\prime n}$, Hypothesis A3 ensures that $\frac{p_{s^{\prime}}^{n}}{p_{s}^{n}}$ can not converge to zero when $n$ goes to infinity, which contradicts that $\hat{p}_{s^{\prime}}=0$.

Q.E.D.

Let us prove that $\left(x^{i}\right)_{i=I+1}^{I+J}$ is optimal for Type $B$ agents for $K$ large enough. Since each agent $i=I+j \geq I+1$ in the initial economy has a strictly convex utility function, the optimal solutions are contained in $\left\{\left(\frac{p \omega^{I+j}}{p_{1}}, 0, \ldots, 0\right), \ldots,\left(0, \ldots, 0, \frac{p \omega^{I+j}}{p_{S}}\right)\right\}$. If we use Lemma A.1, we have that, for $K$ large enough compared with $K^{\prime}, p_{1} \sim 0$ and $p_{s}$ is bounded away from zero for all $s \neq 1$; then, $\frac{p \omega^{I+j}}{p_{1}}$ is large and $\frac{p \omega^{I+j}}{p_{s}}$ is bounded by $2(S-1) K^{\prime}$, and, since $U^{I+j}$ is a strictly convex and strictly increasing function for each $j \leq J$, we have that $U^{I+j}\left(\frac{p \omega^{I+j}}{p_{1}}, 0, \ldots, 0\right) \geq U^{I+j}\left(0, \ldots, 0, \frac{p \omega^{I+j}}{p_{s}}, 0, \ldots, 0\right)$, for all $s \geq 2$, $j=1, \ldots, J$ for $K$ is large compared with $K^{\prime}$; then, his optimal solution coincides with the optimal solution of the agent $I+j$ in the fictitious economy. Therefore, $\left(\left(x^{i}\right)_{i=1}^{I+J}, p\right)$ is an equilibrium for the initial economy for $K$ large enough compared with $K^{\prime}$, which concludes the proof.

Q.E.D.

\section{REFERENCES}

Araujo, A. J.-M. Bonnisseau, A. Chateauneuf, And R. Novinski (2016): "Optimal Sharing With an Infinite Number of Commodities in the Presence of Optimistic and Pessimistic Agents," Economic Theory, 63 (1), 131-157. [1866]

Aumann, R. J. (1966): "Existence of Competitive Equilibria in Markets With a Continuum of Traders," Econometrica, 34 (1), 1-17. [1860,1862]

Borghans, L., A. L. Duckworth, J. J. Heckman, And B. Ter WeEl (2016): “The Economics and Psychology of Personality Traits," The Journal of Human Resources, 43 (1), 972-1059. [1859]

BruHin, A., H. HeHr-DudA, AND T. EPPER (2016): "Risk and Rationality: Uncovering Heterogeneity in Probability Distortion," Econometrica, 78 (4), 1375-1412. [1860]

Chiappori, P.-A., B. Salanié, F. SAlanié, And A. Gandhi (2012): "From Aggregate Betting Data to Individual Risk Preferences," Working Paper. [1860]

FRIEDMAN, M., AND L. J. SAVAGE (1948): “The Utility Analysis of Choices Involving Risk,” Journal of Political Economy, 56, 279-304. [1860]

GilbOA, I., AND D. SCHMEIDLER (1989): “Maxmin Expected Utility With Non-Unique Prior,” Journal of Mathematical Economics, 2, 141-153. [1860]

HE, W., AND N. C. YANNELIS (2016): "Existence of Walrasian Equilibria With Discontinuous, non-ordered, Interdependent and Price-Dependent Preferences," Economic Theory, 61 (3), 497-513. [1865]

Jullien, B., AND B. SAlanié (2000): "Estimating Preferences Under Risk: The Case of Racetrack Bettors," Journal of Political Economy, 108 (3), 503-530. [1859]

Kahneman, D., AND A. TVERSKY (1979): "Prospect Theory: An Analysis of Decision Under Risk," Econometrica, 263-291. [1859,1860]

\footnotetext{
${ }^{11}$ By $\partial U$ we mean the super-differential of the function $U$.
} 
Klibanoff, P., M. MARINACCI, AND S. MukerJi (2005): "A Smooth Model of Decision Making Under Ambiguity," Econometrica, 73 (6), 1849-1892. [1860,1865,1866]

MACCHERONI, F., M. MARINACCI, AND A. Rustichini (2006): "Ambiguity Aversion, Robustness, and the Variational Representation of Preferences," Econometrica, 74 (6), 1447-1498. [1860,1865,1866]

PotAmites, E., AND B. ZhANG (2006): "Heterogeneous Ambiguity Attitudes: A Field Experiment Among Small-Scale Stock Investors in China," Review of Economic Design, 119, 1-21. [1860]

QuigGin, J. (1982): "A Theory of Anticipated Utility," Journal of Economic Behavior \& Organization, 3, 323343. $[1860,1865]$

(1993): Generalized Expected Utility Theory: The Rank-Dependent Model. Boston: Springer Science and Business Media. [1860,1865]

RigotTi, L., C. SHANNON, AND T. STRZALECKI (2008): "Subjective Beliefs and ex ante Trade," Econometrica, 76 (5), 1176-1190. [1866]

SCHMEIDLER, D. (1989): "Subjective Probability and Expected Utility Without Additivity," Econometrica, 57, 571-587. [1860,1865,1866]

SHAFER, W. (1976): "Equilibrium in Economies Without Ordered Preferences or Free Disposal," Journal of Mathematical Economics, 2, 135-137. [1865]

ShANe, S., E. A. LOCKE, AND C. J. Collins (2003): "Entrepreneurial Motivation," Human Resource Management Review, 13 (2), 257-279. [1859]

SNOWBERG, E., AND J. WOLFERS (2010): "Explaining the Favorite-Longshot Bias: Is It Risk-Love or Misperceptions?" Human Resource Management Review, 118 (4), 723-746. [1860]

Trautmann, S. T., AND G. VAN DE Kuilen (2015): "Ambiguity Attitudes," in The Wiley Blackwell Handbook of Judgment and Decision Making, Vol. 1, 89-116. [1860]

TVERSKY, A., AND D. KAHNEMAN (1992): "Advances in Prospect Theory: Cumulative Representation of Uncertainty," Journal of Risk and Uncertainty, 5 (4), 297-323. [1860]

WAKKER, P. (2010): Prospect Theory: For Risk and Ambiguity. Cambridge University Press. [1860]

YAARI, M. E. (1987): “The Dual Theory of Choice Under Risk,” Econometrica, 55 (1), 95-115. [1860,1865]

\section{Co-editor Itzhak Gilboa handled this manuscript.}

Manuscript received 12 October, 2016; final version accepted 17 May, 2018; available online 25 May, 2018. 